\title{
ПСИХОЛОГИЧЕСКИЕ ОСОБЕННОСТИ ОБУЧЕНИЯ ИНОСТРАННОМУ ЯЗЫКУ СТУДЕНТОВ ЭКОНОМИЧЕСКИХ ВУЗОВ
}

\section{PSYCHOLOGICAL FEATURES OF TEACHING A FOREIGN LANGUAGE TO STUDENTS OF ECONOMIC UNIVERSITIES}

\author{
A. Nabiruhina \\ K. Kubacheva \\ N. Gul
}

Summary: This article considers the psychological characteristics of teaching foreign languages to students of economic universities belonging to different psychotypes: extroverts, introverts and ambiverts. The goal of our research was to study the impact of students'psychological characteristics such as abilities, temperament, character and feelings on the quality of assimilation and acquisition of knowledge, the formation of skills and abilities in learning foreign languages. During our study we used various forms of training such as individual, group, frontal, collective, paired, classroom and extracurricular ones. The authors point out that it is necessary to take into account these features when organizing online teaching in e-learning environment of the economic university, which allows to master educational programs remotely, regardless of the time and location of students. As a result of the research, the authors came to the conclusion that the effectiveness of teaching foreign languages for these psychotypes depends both on the forms of training and on the cognitive abilities of students, which affect the process of mastering the educational material when learning foreign languages. Consequently, taking into account the psychological characteristics of students enables the teacher to use them effectively in the process of teaching foreign languages in economic universities.

Keywords: psychological characteristics, training of psychotypes (introverts, extroverts and ambiverts), forms and methods of teaching foreign languages, online training.

\section{Введение}

$\mathrm{B}$ хождение России в глобальную экономическую систему обусловило повышение требований к подготовке специалистов, готовых вести активную совместную деятельность с зарубежными партнерами, используя профессиональную иноязычную компетенцию, путем активного внедрения информационно-коммуникационных технологий в учебный процесс. В связи с этим становится актуальным рассмотрение вопросов, касающихся содержания обучения и соответствующе-
Набирухина Анна Вадимовна

К.филол.н., дочент, Санкт-Петербургский государственный экономический университет

nabirukhina@mail.ru

Кубачева Кабият Ибрагимовна

К.п.н., дочент, Санкт-Петербургский государственный экономический университет gabib101155@mail.ru

Гуль Наталия Владимировна

К.п.н., дочент, Санкт-Петербургский государственный экономический университет

gulnawl@mail.ru

Аннотация: Данная статья посвящена психологическим особенностям обучения в экономическом вузе иностранному языку студентов, относящимся к различным психотипам: экстравертам, интровертам и амбивертам. Целью нашего исследования было изучение того, как психологические особенности студентов, такие как способности, темперамент, характер и чувства влияют на качество усвоения и приобретения знаний, формирование умений и навыков при изучении иностранных языков. В ходе исследования применялись различные формы организации обучения: индивидуальные, групповые, фронтальные, коллективные, парные, аудиторные и внеаудиторные. Авторы указывают на необходимость учета данных особенностей при организации онлайн-обучения в электронной информационно-образовательной среде вуза, которая позволяет освоить образовательные программы в дистанционном режиме независимо от времени и места нахождения студентов. В результате проведенного исследования авторы пришли к выводу, что эффективность обучения иностранным языкам указанных психотипов зависит как от форм обучения, так и от познавательных способностей студентов, влияющих на процесс овладения учебным материалом при обучении иностранному языку. Следовательно, учет знаний психологических особенностей студентов дает возможность преподавателю эффективно использовать их в процессе преподавания иностранных языков в экономических вузах.

Ключевые слова: психологические особенности, обучение психотипов (интроверты, экстраверты и амбиверты), формы и методы обучения иностранному языку, онлайн-обучение.

го современного аутентичного учебного материала, с учетом психологических особенностей студентов экономических вузов, и внедрения рациональных организационных форм в соответствии с уровнем владения иностранным языком.

Владение иностранным языком способствует интеграции в мировое экономическое пространство, позволяет получать информацию, осуществлять коммуникацию в устной или письменной форме - и таким образом, соответствовать требованиям, предъявляемым совре- 
менным рынком труда.

Сегодня в системе образования в целом и в экономических вузах, в частности, наблюдаются изменения, которые ставят перед профессорско-преподавательским составом ряд определенных задач.

Данные задачи, касающиеся таких проблем, как использование рациональных организационных форм обучения с учетом психологических особенностей студентов, относящихся к различным психотипам: экстравертам, интровертам и амбивертам, решаются с помощью отбора соответствующего учебного материала, отвечающего современным требованиям федерального государственного образовательного стандарта высшего профессионального образования (ФГОС ВПО). Немаловажным оказывается индивидуальный подход с учетом психологических особенностей подготовки студентов в экономических вузах. [13,14].

Особенно остро данная проблема проявилась во время дистанционного обучения в период пандемии коронавируса - COVID-19, тогда и выяснилось, что в отличие от аудиторных занятий «face to face», каждый студент получил возможность воспринимать и обрабатывать учебный материал в своем темпе, в соответствии со своими индивидуальными психологическими особенностями.

Следует отметить, что актуальность данной статьи обусловлена возникшими изменениями не только в системе образования в целом, а также при обучении каждого студента во время «lockdown».

Цель нашего исследования состояла в разработке концепции индивидуального подхода с учетом психологических особенностей при обучении студентов иностранным языкам в экономических вузах, принадлежащих к разным личностным психотипам.

Анализируя данные вопросы значимости индивидуального подхода, мы разделяем точку зрения Г.К. Селевко, который указывает, что «индивидуализация обучения - это организация учебного процесса, при которой выбор способов, приемов, темп обучения обусловливается индивидуальными психологическими особенностями обучающихся» [6]. Считаем, что учет психологического аспекта при индивидуальном подходе к организации учебного процесса требует принять во внимание личностную характеристику, интеллектуальное развитие, познавательный интерес, мотивацию и психотип личности. Таким образом на успешность обучения оказывают большое влияние данные факторы.

Н.В. Баграмова рассматривает совокупность наиболее важных индивидуальных особенностей обучаемых, учет которых может способствовать или препятствовать эффективному усвоению иностранного языка, предлагая некоторые рекомендации, помогающие на практике реализовать учет этих особенностей [2]. Мы считаем, что актуальность учета психологических особенностей студентов при обучении иностранному языку в экономических вузах определена различиями индивидуальных особенностей психотипов.

Исходя из многолетнего опыта преподавания иностранного языка в экономическом вузе, можно констатировать, что способности студентов к его изучению не всегда одинаковы: одним дается овладение иностранным языком легко, в то время как у других оно становится проблемным. Следует признать, что существуют различия в усвоении материала у экстравертов, интровертов и амбивертов. Анализируя интересы и способности психотипов, а также перспективы развития их способностей, следует признать, что они являются ключевым моментом при обучении иностранному языку. В большинстве случаев, на практических занятиях по иностранному языку учитываются психологические особенности психотипов: экстравертов, интровертов и амбивертов. Необходимо подчеркнуть, что индивидуализация обучения студентов экономических вузов носит не только эпизодический, но и системный характер.

Мы полагаем, что системная индивидуальная работа должна заранее планироваться с учетом психологических особенностей студентов и их принадлежности к разным личностным психотипам.

Впервые понятие «экстраверсия - интроверсия» было введено Карлом Юнгом начале XX века для обозначения двух противоположных типов личности. При формулировке определения данных психотипов учитывались психологические особенности обучающихся: коммуникабельность, разговорчивость, честолюбие, напористость, активность и др. [9].

В своих научных трудах Г. Айзенк подчеркивает импульсивность экстравертов, имеющих склонность к риску, в то время как интроверты - неимпульсивны, им присущи заблаговременное планирование своих действий, соблюдение моральных и этических норм и трудности в общении [1].

Особое внимание Р.М. Фрумкина уделяет разным видам памяти в своих исследованиях по психолингвистике [7]. На основе анализа исследований Е. Хорвата и Г. Айзенка, она сделала вывод, что у экстравертов лучше развита кратковременная память, а у интровертов - долговременная [12; 1$]$.

В результате проведенного исследования, Р. Драммондом и А. Стоддартом, было обнаружено, что экстраверты не склонны к последовательности, логичности, научности и аналитичности мышления, в то время как 
для интровертов характерна противоположная картина [11].

Немалый интерес вызвали труды В.В. Белоуса, который определил разные уровни успешности выполнения деятельности, связанной с приемом и переработкой информации определенного и неопределенного содержания у экстравертов и интровертов [3].

Е.П. Ильин в своих исследованиях указывает, что у каждого человека есть черты как экстравертированного, так и интровертированного типа. И лишь соотношение этих черт дает возможность различить их между собой [5].

Существует психотип, который владеет чертами характера как интроверта, так и экстраверта одновременно, это амбиверт, личность, характеризующаяся способностью адаптироваться к любым условиям в обществе. Они легко переходят из одного психологического состояния в другое, от замкнутости, характерной интровертам, до общительности, присущей экстравертам. Умение приспосабливаться к ситуации, чувствуя себя одинаково комфортно, общаясь с окружающими либо пребывая длительное время в полном одиночестве помогает им выполнять различные виды как коммуникативных, так и письменных заданий.

В методике и дидактике преподавания иностранных языков существует огромное количество психологических исследований, посвященных особенностям обучения студентов иностранным языкам.

Тем не менее, недостаточно изучен вопрос обучения студентов экономических вузов с учетом психологических особенностей.

Мы попытались рассмотреть в нашем исследовании личностные психотипы студентов, которые, по нашему мнению, наиболее распространены и важны при обучении иностранным языкам в вузе.

При проведении анкетирования Г. Айзенка мы применили двухфакторную модель измерения экстравертированности и эмоциональной устойчивости. На сайте Тестометрика https://testometrika.com/temperament/ test-to-determine-introvert-and-extrovert-g-eysenck/ студенты прошли онлайн тестирование, интерпретация результатов проводилась на основе психологических характеристик личности, с учетом степени выраженности психологических свойств.

По результатам анкетирования было выявлено, что среди студентов 60 \% составляют экстраверты, 25 \% яркие экстраверты, 13 \% интроверты, 3 \% глубокие интроверты и 27 \% амбиверты, которым присущи черты обоих типов и они могут ситуативно проявлять качества и тех и других.

На основе выявленных типичных психических характеристик для каждого психотипа, мы разработали концепцию индивидуального подхода с учетом психологических особенностей и использовали ее в процессе обучения.

Исходя из опыта иностранных и отечественных педагогов (Л.С. Выготский, А.С. Шляхина, В.А. Якунин) мы рассмотрели психотипы на психологическом, интеллектуальном и коммуникативном уровнях $[4 ; 8 ; 10]$. Последний уровень является наиболее важным при изучении иностранного языка.

\section{Методы}

На основе проведенного анализа мы определили методы и приемы обучения иностранным языкам в экономическом вузе, которые, на наш взгляд, являются наиболее эффективными при формировании иноязычной коммуникативной компетенции у студентов, относящихся к разным психотипам. При формулировке заданий мы принимали во внимание тот факт, что экстраверты показывают более высокие результаты при применении интерактивного подхода к обучению, а интроверты более успешно применяют аналитический подход к выполнению заданий.

Так, например, при обучении чтению аутентичных текстов по специальности необходимо учитывать, с одной стороны, релевантность содержания для аналитической работы с информацией, и, с другой стороны, возможность использования текста для развития навыков общения. Тема текста должна иметь как реальную профессиональную значимость для студентов, так и личностную значимость, стимулировать желание обмениваться информацией и активно вовлекать студентов в процесс коммуникации.

На этапе выполнения предтекстовых упражнений мы готовили студентов к выбору определенной стратегии работы с текстом, акти-визируя имеющиеся у них знания по данной экономической проблеме и вызывая заинтересованность в прочтении текста.

Приведем примеры предтекстовых упражнений к аутентичной статье по инвестиционному менеджменту. Интроверты с большей готовностью выполняли предтекстовые упражнения, направленные на догадку о содержании текста по заглавию или содержащие общие вопросы, выявляющие их фоновые знания по обсуждаемой проблеме:

"Read the title of the article and the short introductory text. What topic do you think will be covered in the article? What kind of information will you find there?» 
"Before reading the text, consider each of the subtitles of the article. Use your knowledge to comment on the risks, returns and costs of a bond fund».

«What types of bonds do you know? What are their advantages and disadvantages?»

Экстраверты успешно выполняли задания, в которых надо было выразить свое собственное мнение по поводу тематики предложенного текста и ответить на более индивидуализированные вопросы, выясняющие их интересы и предпочтения:

"Before you read the article, share your opinion on the problem using your own ideas and experience».

"As an investor, why would you like to buy bonds? What types of bonds would you like to introduce into your portfolio and why?»

«Do you know what kind of investor you are?»

В системе коммуникативного иноязычного образования преподаватель должен воссоздавать на занятии ситуации, являющиеся моделью реального процесса общения на рабочем месте, поэтому особое значение приобретает применение различных практико-ориентированных методов, таких, как имитация делового общения, деловые и ролевые игры, анализ кейса, проект. При реализации этих коммуникативно-интерактивных методов также необходимо учитывать психотипы студентов в группе.

Рассмотрим пример деловой игры по финансовому консультированию. Экстраверты, которые характеризуются общительностью, оптимистичностью, чувствуют себя раскованно в процессе речевого общения, отлично справляются с ролью «консультанта», который должен свободно выразить свое мнение, быстро и гибко реагировать на высказывания и пожелания «клиента», используя различные коммуникативные стратегии и тактики. В то же время, интроверты увереннее выполняют роль «клиента» - они могут заранее проанализировать заданную ситуацию, продумать типовые вопросы и спланировать беседу.

В зависимости от своего психотипа студенты поразному интерпретируют ситуации профессионального общения, предложенные для анализа (метод Case study). Так, при анализе кейса по приему на работу в компанию и при выполнении задания по отбору персонала, студенты выбирают кандидатов для успешной работы на должности в соответствии со своим психотипом. В группе, где преобладают интроверты, для кейса следует подобрать ситуацию в компании в сфере бизнес-консультирования и аналитики, в то время как в группе с преобладанием экстравертов с большим успехом пройдет деловая игра о компании в области PR, маркетинга, рекламы.

В последнее десятилетие в наших вузах успешно интегрируются инновационные педагогические техно- логии и информационно-коммуникационные методы обучения. Комплексное и системное внедрение компьютерных технологий в учебный процесс позволяет находить более эффективные подходы к решению традиционных задач формирования иноязычной коммуникативной компетенции. С 2015 года мы используем систему дистанционного обучения MOODLE для методического сопровождения обучения иностранному языку по всем направлениям подготовки, для разработки дистанционных курсов, для тестирования обучающихся в целях распределения их на гомогенные по уровню группы и постоянного мониторинга прогресса в обучении.

В марте 2020 года в период пандемии коронавируса вышел приказ о переходе вузов города на дистанционное обучение, и наши преподаватели смогли слаженно перейти на эту форму обучения благодаря уже накопленному опыту организации онлайн-обучения в электронной информационно-образовательной среде (ЭИОС) вуза. Параллельно с использованием уже апробированных курсов в ДСО MOODLE мы начали активное применение платформ для проведения видеоконференций Zoom и Big Blue Button. Это позволило вести занятия в режиме онлайн, обеспечило взаимодействие с обучающимися и реализацию образовательных программ в дистанционном режиме.

Следует отметить, что адаптация студентов к новым условиям обучения также проходила по-разному в зависимости от их психотипа. Несмотря на то, что режим видеоконференций дает возможность для применения практико-ориентированного подхода и развития навыков устной речи, экстраверты высказывали мнение о предпочтении аудиторных занятий и живой коммуникации с преподавателем и группой, однако они быстро включались в групповую работу на электронных платформах. Интроверты чувствовали себя достаточно комфортно и уверенно, с увлечением используя технические возможности компьютерного обучения. Работая в СДО MOODLE, интроверты предпочитали применение элемента курса «Форум», так как он позволяет участникам общаться в асинхронном режиме, в своем темпе, в течение длительного времени. Экстраверты были склонны использовать элемент «Чат», дающий возможность синхронного письменного общения, то есть спонтанного общения в режиме реальном времени.

Информационно-коммуникационные технологии предоставляют исключительные возможности для организации обучающих проектов по английскому языку во внеаудиторное время. Для более эффективного формирования общекультурных и профессиональных компетенций студентам необходимо приобретать собственный практический опыт обсуждения и решения проблем в международной команде. Мы предложили нашим студентам использовать компьютерные технологии для 
моделирования профессиональной коммуникации с их будущими коллегами - иностранными студентами-экономистами. Студенты могли встретиться на видеоконференции, используя платформу ZOOM, что способствовало формированию навыков устной речи, а общение по электронной почте улучшало навыки письменной речи. Данные проекты профессионального межкультурного общения студентов были интересны для всех психотипов в одинаковой степени. Однако, экстраверты активнее вели обсуждение профессиональных проблем на платформе ZOOM, в то время как интроверты выбирали электронную почту для установления контакта, что касается амбивертов, они с удовольствием включались в любые виды деятельности.

\section{Выво $\Delta ы$}

Таким образом, можно с уверенностью говорить о том, что современном мире учет психологического аспекта при изучении иностранных языков становится особенно актуальным. Исследования показали, что экстравертам и интровертам нужны разные формы обучения иностранным языкам: для одних погружение в языковую среду было эффективным, для других, скорее, скучным. Экстравертам лучше удавались коллективные формы работы, а интроверты предпочитали выполнять работу в индивидуальном режиме. Амбиверты же, сочетающие в себе качества интроверта и экстраверта, прекрасно чувствовали себя при выполнении заданий как в индивидуальной, так и в коллективной работе.

Наиболее эффективными для экстравертов методами обучения иностранному языку являлись интерактивные формы работы, как в формате «оffline», так и «online», в то время как интровертам лучше удавались задания - аналитического типа.

Успешность иноязычной профессиональной коммуникации, как показало исследование, связано в основном с экстравертированностью, так как обучаемые с данными свойствами личности обладают более сформированной коммуникативной компетенцией и у них лучше развито творческое мышление.

В ходе исследования нами была сделана попытка решить следующие задачи:

- приблизить обучение к идеальным условиям, постараться обеспечить каждому студенту максимально комфортные методы и формы обучения;

- осуществить нивелирование разницы в коммуникативной подготовке у экстравертов и интровертов, используя различные виды заданий с учетом их психологических особенностей.

Таким образом, индивидуальный подход и знание типичных особенностей психотипов студентов позволяют преподавателям эффективно использовать их в процессе преподавания иностранных языков в экономических вузах и приводят к положительным результатам.

ЛИТЕРАТУРА

1. Айзенк Г. Парадоксы психологии = Psychology is about people. - М.: Эксмо-Пресс, 2009. - 352 c.

2. Баграмова Н.В., Костина Е.А. Индивидуальные психологические особенности обучаемых, влияющие на эффективность овладения иностранным языком. //Актуальные проблемы филологии и методики преподавания иностранных языков. - 2018. - № 12. - С. 60-65.

3. Белоус В.В. Введение в психологию полиморфной индивидуальности: монография. - 5-е изд., перераб. и доп. М.: Кнорус, 2016. - 268 с.

4. Выготский Л.С. Педагогическая психология / под ред. В.В. Давыдова. - М.: Изд-во АСТ, 2010. - 671с.

5. Ильин Е.П. Дифференциальная психофизиология: учеб. пособие для вузов. - М.: Академия, 2011. - 144 с.

6. Селевко Г.К. Энциклопедия образовательных технологий: в 2 т. -Т. 1. -М.: НИИ школьных технологий, 2006. -816 с.

7. Фрумкина Р.М. Психолингвистика: учеб. для студ. высш. учеб. заведений. - М.: Академия, 2001. - 320 с.

8. Шляхина А.С. Психологические особенности студентов неязыкового вуза при обучении иностранному языку. // Молодой ученый. - 2010. - № 3(14). C. 312-314.

9. Юнг К.Г. Психологические типы: научное издание. - 2-е издание. - М.: Прогресс-Универс, 2015. - 715 с.

10. Якунин В.А. Педагогическая психология: учеб. пособие. /Европеский институт экспертов. - СПб.: Изд-во Михайлова В.А., 2000. - 132 с.

11. Drummond R., Stoddard A. Learning Style and Personality Type. // Robert J. Drummond, Ann H. Stoddard. / Percept Motor Skills. - 2002. - Vol. 75(1) - P. 99-104

12. Howarth E. Personality differences in serial learning under distraction. // Elsevier Science \& Technology,2001. - P. 379-382.

13. Kubacheva K.I., Baeva T.A. Teaching foreign language students sociotypes' (extroverts and introverts) personal characteristics in non-linguistic faculties.// Journal of Teaching English for Specific and Academic Purposes. - 2017. - T.5. - № 2. - C. 317-320.

14. Stojkovic N., Kubacheva K.I., Baeva T. A Importance of psychological aspect in foreign language teaching at non-linguistic master's academic studies. / N.Stojkovic, K.I. Kubacheva, Т.A. Ваеva. // Создание искусственного иноязычного окружения как один из факторов активизации учебной деятельности: мат-лы всерос. науч.-практ. конф. С междунар. участ. - СПб.: Изд-воСПбЭУ, 2019. - С. 77-81.

$$
\begin{gathered}
\text { (c) Набирухина Анна Вадимовна (nabirukhina@mail.ru), Кубачева Kaбият Ибрагимовна (gabib101155@mail.ru), } \\
\text { Гуль Наталия Владимировна (gulnawl@mail.ru). } \\
\text { Журнал «Современная наука: актуальные проблемы теории и практики» }
\end{gathered}
$$

